\title{
Class attendance and cardiology examination performance: a study in problem-based medical curriculum
}

This article was published in the following Dove Press journal:

International Journal of General Medicine

9 February 2016

Number of times this article has been viewed

\author{
Samira S Bamuhair' \\ Ali I Al Farhan ${ }^{1,2}$ \\ Alaa Althubaiti' \\ Saeed ur Rahman ${ }^{1,2}$ \\ Hanan M Al-Kadri' ${ }^{1,3}$ \\ 'College of Medicine, King Saud Bin \\ Abdulaziz University for Health \\ Sciences, ${ }^{2}$ Department of Family \\ Medicine and Primary Health Care, \\ ${ }^{3}$ Department of Obstetrics and \\ Gynecology, King Abdulaziz Medical \\ City, Riyadh, Saudi Arabia
}

Correspondence:Alaa Althubaiti College of Medicine, King Saud Bin Abdulaziz University for Health Sciences, Mail code 3I27, Riyadh I |48I, PO Box 22490, Riyadh, Saudi Arabia Tel +966 I 2520088 Email thubaitia@ksau-hs.edu.sa
Background and aims: Information on the effect of students' class attendance on examination performance in a problem-based learning medical curriculum is limited. This study investigates the impact of different educational activities on students' academic performance in a problembased learning curriculum.

Methods: This is a retrospective cohort study conducted on the cardiology block at the College of Medicine, King Saud Bin Abdulaziz University for Health Sciences, Riyadh, Saudi Arabia. All students who undertook the cardiology block during the academic year 2011-2012 were included. The students' attendance was measured using their overall attendance percentage. This percentage is a product of their attendance of many activities throughout the block. The students' performance was assessed by the final mark obtained, which is a product of many assessment elements. Statistical correlation between students' attendance and performance was established.

Results: A total of 127 students were included. The average lecture attendance rate for the medical students in this study was found to be $86 \%$. A significant positive correlation was noted between the overall attendance and the accumulated students' block mark $(r=0.52 ; P<0.001)$. Students' attendance to different education activities was correlated to their final mark. Lecture attendance was the most significant predictor $(P<0.001)$, that is, $1.0 \%$ increase in lecture attendance has predicted a 0.27 increase in students' final block mark.

Conclusion: Class attendance has a positive effect on students' academic performance with stronger effect for lecture attendance compared to attendance in other teaching modalities. This suggests that lecture attendance is critical for learning even when a problem-based learning medical curriculum is applied.

Keywords: class attendance, academic performance, problem-based learning

\section{Introduction}

The relationship between class attendance of college students and their academic performances is well documented in the literature. Several studies have reported that class attendance has a positive impact on academic performance. ${ }^{1}$ This relationship suggested that dramatic improvements in average grades and failure rates could be achieved by efforts to increase class attendance rates among college students. Meeting with absent and underperforming students at the earliest possible opportunity has proved to be an effective way of promoting dialogue between staff and students particularly those experiencing difficulties. ${ }^{2}$

However, studies on the relationship between class attendance and students' academic performances have focused on the effect of students' attendance in traditional lecture-based knowledge delivery methods. ${ }^{3-7}$ In recent years, the use of nontraditional 
instructional methods in medical curricula has increased rapidly. These nontraditional teaching modalities include problem-based learning (PBL), student-centered curricula, and team working. There is a fundamental difference in knowledge delivery methods between traditional and nontraditional curricula. This could make academic performance even more sensitive to class attendance when active studentcentered teaching methods are utilized. ${ }^{8}$

Literature review shows that the effect of nontraditional teaching modalities on students' academic performance compared to lecture-based teaching curricula is evasive., ${ }^{9,10}$ For example, PBL has been utilized widely as a learning approach in medical education and has helped students acquire improvement in academic performance. ${ }^{11,12}$ However, when compared to traditional class-based knowledge delivery methods such as lecture-based instructional methods, PBL has not always improved academic performance. ${ }^{13,14}$

The aim of this study is to investigate the impact of class attendance in different educational activities on students' academic performance in a PBL, student-centered curriculum.

\section{Methodology}

\section{Study design and settings}

This is a retrospective cohort study. The study was conducted in the College of Medicine, King Saud Bin Abdul Aziz University for Health Sciences, Riyadh. The university accepts both high school and university graduates. The duration of the medical college program is six academic years for stream one (high school graduates) and $4 \frac{1}{3}$ academic years for stream two (university graduates) with three sequential phases. Phase I: Premedical, Phase II: Medical, and Phase III: Clinical Clerkship. The curriculum is PBL, community-oriented, integrated, and student-centered. The components of this curriculum have been organized in sequential blocks (modules) with early exposure to patients and case management. Throughout the curriculum, the medical program is organized around four themes; basic and clinical sciences (BCS), patient and doctor theme, community and doctor theme, and personal and professional development.

BCS theme is the most substantial theme, covering the scientific knowledge base required for medical practice. It includes pre- and para-clinical disciplines (eg, anatomy) as well as clinical disciplines (eg, surgery). Patient and doctor theme covers the range of clinical skills that students need to acquire - the motions that doctors go through when actually dealing with patients. Community and doctor theme covers health issues of the wider population, locating the practice of medicine in a wider social context. Personal and professional development deals with medicine as a profession, and teaching skills that are required to fare in the medical workforce (eg, teamwork and stress management) as well as in the wider profession (eg, maintaining scholarly connections).

The emphasis is on progressive development across all four themes in the knowledge, skills, and attitude appropriate for a graduate. Self-directed learning represents the core of the program and is supported by scheduled weekly sessions: three PBL sessions (each 1.5 hours), and up to five lectures per week related to the weekly problem issues relevant to all themes with an emphasis on BCS sessions. Lecture and other teaching activities topics are related to the weekly problems and are guided by the block objectives. There is a major focus on the critical appraising of the evidence that underpins medical decision-making.

Throughout the block, students are assessed continuously during each and every PBL session where a checklist is filled out by their session tutor and the overall mark of the 18 PBL sessions conducted represents $15 \%$ of the student final block mark. Multiple choice questions (MCQs) examinations are created based on the material presented in the lectures and are conducted twice during the block (midterm and final MCQ exams). The midterm exam consists of $40 \mathrm{MCQ}$, and the final exam consists of $80 \mathrm{MCQs}$. Students are also assessed through Objective Structured Clinical Examination and Objective Structure Practical Examination. The objectives included in these two exams are delivered during the BCS sessions, community and doctor theme presentations, and personal and professional development presentations.

We included all students who undertook the cardiology block during the academic year 2011-2012. Not all blocks or courses were included in the study since outcome from different courses cannot be joined together and there were different attendance elements between courses.

The academic record of each student was reviewed. Students' attendance percentage to different educational activities and their overall attendance during the block were obtained. Students' examination scores in each assessment conducted were also recorded. The students' overall academic performance in this study is based on the accumulative results of the comprehensive exams throughout the block and those conducted at the end of the block. The outcome considers $\geq 60 \%$ as passing score, and less than $60 \%$ as failure. Students who were absent during their final examination due to any reason were excluded from the analysis. The candidate's percentage of class attendance is considered before allowing a candidate to appear at the examination. 
Table I Attendance of sessions for which the curricula themes were delivered

\begin{tabular}{llllll}
\hline $\begin{array}{l}\text { Attendance } \\
\text { elements }\end{array}$ & Number of sessions & Minimum (\%) & Maximum (\%) & Mean (\%) & $\begin{array}{l}\text { Standard } \\
\text { deviation }\end{array}$ \\
\hline Overall & 104 & 63 & 100 & 86.1 & 7.2 \\
PBL & 18 & 61 & 100 & 97.6 & 5.7 \\
Lecture & 42 & 62 & 100 & 85.5 & 10.8 \\
BCS sessions & 21 & 65 & 100 & 86.5 & 8.7 \\
PPD presentation & 3 & 0 & 100 & 66.7 & 27.5 \\
CS sessions & 18 & 60 & 100 & 92.4 & 10.8 \\
CDT presentation & 2 & 0 & 100 & 66.9 & 36.3 \\
\hline
\end{tabular}

Abbreviations: BCS, basic and clinical sciences; CDT, community and doctor theme; CS, clinical skills; PBL, problem-based learning; PPD, personal and professional development.

A minimum attendance of $75 \%$ during an academic session is considered eligible for sitting the college examination. As part of the college policy, the students are regularly encouraged to attend all the teaching and learning activities.

The study was approved by the Institutional Review Board of King Abdullah International Medical Research Centre. As this was a retrospective study, students' consent was not required.

\section{Statistical analysis}

All students' attendance percentages and their assessment results are described using mean and standard deviation (SD). Independent Student's $t$-test was used to explore sex differences regarding attendance and performance. Pearson correlation $(r)$ was utilized to explore the association between attendance elements and the final mark achieved. Simple regression was used to predict the effect of overall attendance on the students' final marks. A single step multiple regression was used to examine the effect of significantly associated attendance elements with the final marks. The coefficient of determination $\left(R^{2}\right)$ is reported as a measure of goodness-of-fit. All statistical tests used were two-tailed. A $P$-value of 0.05 or less was considered statistically significant. The data were analyzed using the Statistical Package for the Social Sciences, Version 20.0 (IBM Corporation, Armonk, NY, USA).

\section{Results}

A total of 127 students were included in the study of whom $90(71.0 \%)$ were male students. The students' attendance was measured by the overall attendance percent (mean $=86.1 \%$, $\mathrm{SD}=7.2$ ), which is a product of attending various activities throughout the block. Table 1 provides a summary of the attendance percentage of each of the different educational activities. The students' performance was assessed by the final mark obtained (mean $=82.8, \mathrm{SD}=8.7$ ). The final mark is a product of many assessment elements, which is summarized in Table 2.

\section{Sex}

No significant differences were noted between male and female students. Although male students had a slightly higher overall attendance $(86.2 \%)$ compared to female students (85.7\%), female students were able to achieve a slightly higher final mark (84.4) compared to only 82.2 among the male students. All these differences were not statistically significant.

\section{Correlation between examination performance and attendance}

A significant positive correlation was found between the overall attendance and final mark $(r=0.52 ; P<0.001)$. Most of the individual attendance elements also correlated positively and significantly with the final mark (Table 3).

\section{Simple linear regression analysis}

Simple linear regression analysis between overall attendance and final mark shows that overall attendance significantly contributed $27.0 \%$ of the variation in the final mark. The regression model shows that for each $1.0 \%$ increase in the overall attendance, the final mark is expected to increase by 0.63 . The equation obtained from the regression model is:

Final mark $=28.5+(0.63 \times$ overall attendance $)$.

Table 2 Summary of academic performance

\begin{tabular}{lllll}
\hline Assessment & Full mark & Minimum & Maximum & $\begin{array}{l}\text { Mean (standard } \\
\text { deviation) }\end{array}$ \\
\hline Midterm & 25 & 10 & 25 & $19.2(3.2)$ \\
PBL & 15 & 8 & 15 & $14.2(1.3)$ \\
Final written & 30 & 12 & 29 & $23.2(3.5)$ \\
OSCE & 15 & 10 & 15 & $13.2(1.0)$ \\
OSPE & 15 & 8 & 15 & $12.9(1.4)$ \\
Final mark (\%) & 100 & 58 & 97 & $82.8(8.7)$ \\
\hline
\end{tabular}

Abbreviations: OSCE, Objective Structured Clinical Examination; OSPE, Objective Structured Practical Examination; PBL, problem-based learning. 
Table 3 Correlations between final mark and attendance elements

\begin{tabular}{lll}
\hline Attendance elements & $\begin{array}{l}\text { Pearson correlation } \\
\text { coefficient }\end{array}$ & P-value \\
\hline Overall & $0.52^{*}$ & $<0.001$ \\
PBL & $0.25^{*}$ & 0.004 \\
Lecture & $0.47^{*}$ & $<0.001$ \\
BCS sessions & $0.49 *$ & $<0.001$ \\
PPD presentation & -0.07 & 0.468 \\
CS sessions & $0.29 *$ & 0.001 \\
CDT presentation & 0.00 & 0.997 \\
\hline
\end{tabular}

Note: *Significant Pearson correlation.

Abbreviations: $\mathrm{BCS}$, basic and clinical sciences; $\mathrm{CDT}$, community and doctor theme; CS, clinical skills; PBL, problem-based learning; PPD, personal and professional development.

Therefore, according to the regression model equation, a student with $75 \%$ attendance (the minimum required to sit for the final exam) is expected to achieve a final mark of 75.8 .

\section{Multiple regression analysis}

Attendance elements, which were significantly correlated with the final mark, were entered into the regression equation using single step forced entry method (Table 4$)$. The regression model significantly predicted $36 \%\left(R^{2}=0.36\right)$ of the final mark of the students. The results indicated that all attendance elements (PBL, lecture, BCS, and clinical skills) significantly predicted the final mark, with the lecture attendance being the most significant predictor, that is, $1.0 \%$ increase in lecture attendance predicts a 0.27 increase in the final mark of the student $(P<0.001)$. The equation obtained from the model is:

Final mark $=3.4+(0.25 \times \mathrm{PBL}$ attendance $)+(0.27 \times$ lecture attendance $)+(0.24 \times \mathrm{BCS}$ attendance $)+(0.13 \times$ clinical skills attendance).

\section{Discussion}

This study showed a positive correlation between student attendance and examination performance. In fact, the equation given in the "Results" section indicates that each $1.0 \%$ increase in lecture attendance results in an $\sim 0.27 \%$ improvement in the final mark of the student, which compares favorably to other studies. ${ }^{10,15}$ Stating this does not ignore the importance of clinical, and practical training of our medical graduates to function as excellent physicians and not only rely on the good final mark achievements as the literature review showed little correlation between the final mark and later
Table 4 Multiple regression analysis of predictors of academic performance among medical students

\begin{tabular}{lllll}
\hline $\begin{array}{l}\text { Independent } \\
\text { variable }\end{array}$ & $\mathbf{B}(\mathbf{9 5 \%} \mathbf{C I})$ & $\begin{array}{l}\text { Standard } \\
\text { error }(\mathbf{B})\end{array}$ & Beta & P-value \\
\hline Intercept & $3.42(-21.1,28)$ & 12.4 & - & 0.783 \\
PBL attendance & $0.25(0.22,0.48)$ & 0.12 & 0.16 & 0.032 \\
Lecture attendance & $0.27(0.13,0.40)$ & 0.07 & 0.33 & $<0.001$ \\
BCS attendance & $0.24(0.06,0.40)$ & 0.09 & 0.23 & 0.010 \\
CS attendance & $0.13(0.23,0.24)$ & 0.06 & 0.19 & 0.018 \\
\hline
\end{tabular}

Abbreviations: $\mathrm{BCS}$, basic and clinical sciences; $\mathrm{Cl}$, confidence interval; $\mathrm{CS}$, clinical skills; PBL, problem-based learning.

career performance. ${ }^{16}$ Our data indicate that we still depend on the teacher supervision approach in order to achieve a good academic performance. The influence of sex on the relationship between attendance and academic performance is conflicting within the literature. ${ }^{1}$ In the current study, no significant differences were noted between male and female students. Although male students had a slightly higher overall attendance (86.2\%) compared to female students (85.7\%), female students were able to achieve a slightly higher final mark (84.4) compared to male students (82.2).

Many studies found that attendance policy has a strong impact on reducing absenteeism. In our study, a high attendance rate $(86 \%)$ was found in the presence of an attendance policy and academic context that encourage regular attendance. This finding suggests that medical students still regard attendance during different educational activities as educationally valuable. Another possible explanation is that in PBL curriculum, several active-learning techniques and an integrated approach are needed in order to gain a comprehensive understanding, all of which make it difficult for the student to compensate for absences.

It is important to point out, although lecture attendance is one of the many factors that influence academic performance, ${ }^{17}$ lecture attendance remains a significant component of medical education, and students should be encouraged to attend lectures. This is particularly important in PBL curricula where students are obliged to attend various academic activities.

There are two limitations in this study. First, due to the attendance policy at the school, students who were present less than $75 \%$ during an academic session were not allowed to take part in the exam. Therefore, students with low attendance were excluded from the study, while it would have been interesting to measure their academic performance. Second, this study is observational and based on a set of data at one institution. Therefore, our findings are in need of replication and confirmation. Researchers are encouraged to 
test the conclusions at their own institution, especially since attendance policy and courses vary between institutions.

\section{Conclusion}

The analysis of the students' attendance in different educational activities offered to the students, including lectures and their academic performance in a PBL-based curriculum, shows clearly that attendance has a positive effect on the academic performance with a stronger effect for lectures compared to other teaching modalities. This suggests that lecture attendance can be critical for learning even when using nontraditional methods of education.

\section{Acknowledgments}

The authors wish to thank King Saud Bin Abdulaziz University for Health Sciences, Riyadh, for providing the required data for the study.

\section{Disclosure}

The authors report no conflicts of interest in this work.

\section{References}

1. Credé M, Roch SG, Kieszczynka UM. Class attendance in college a meta-analytic review of the relationship of class attendance with grades and student characteristics. Rev Educ Res. 2010;80(2):272-295.

2. Bevitt D, Baldwin C, Calvert J. Intervening early: attendance and performance monitoring as a trigger for first year support in the biosciences. Biosci Educ. 2010;15(6):1-14.

3. Roby DE. Research on school attendance and student achievement: a study of Ohio schools. Educ Res Quart. 2004;28(1):4-15.

4. Khan HU, Khattak AM, Mahsud IU, et al. Impact of class attendance upon examination results of students in basic medical sciences. J Ayub Med Coll Abbottabad. 2003;15(2):56-58.
5. Thatcher A, Fridjhon P, Cockcroft K. The relationship between lecture attendance and academic performance in an undergraduate psychology class. S Afr J Psychol. 2007;37(3):656-660.

6. Romer D. Do students go to class? Should they? J Econ Perspect. 1993;7(3):167-174.

7. Hamdi A. Effects of lecture absenteeism on pharmacology course performance in medical students. J Int Assoc Med Sci Educ. 2006;16:27-30.

8. Gal B, Busturia I, Garrido C. To be or not to be: the importance of attendance in integrated physiology teaching using non-traditional approaches. BMC Res Notes. 2011;4:360.

9. Smith M, Cook K. Attendance and achievement in problem-based learning: the value of scaffolding. IJPBL. 2012;6(1):129-152.

10. Tlhoaele M, Hofman A, Winnips K, Beetsma Y. The impact of interactive engagement methods on students' academic achievement. HERD. 2014;33(5):1020-1034.

11. Foord-May L. A faculty's experience in changing instructional methods in a professional physical therapist education program. Phys Ther. 2006;86(2):223-235.

12. Strobel J, Van Barneveld A. When is PBL more effective? A metasynthesis of meta-analyses comparing PBL to conventional classrooms. IJPBL. 2009;(3):48-55.

13. Smits PBA, Verbeek JHAM, de Buisonjé CD. Problem based learning in continuing medical education: a review of controlled evaluation studies. BMJ. 2002;324(7330):153-156.

14. Hartling L, Spooner C, Tjosvold L, Oswald A. Problem-based learning in pre-clinical medical education: 22 years of outcome research. Med Teach. 2010;32(1):28-35.

15. Lockwood P, Guppy C, Smyth R. Should lectures be compulsory? Proceedings of the UniServe Science Assessment Symposium; 2006. Available from: http://science.uniserve.edu.au/pubs/procs/2006/lockwood.pdf. Accessed May, 2011.

16. Wingard JR, Williamson JW. Grades as predictors of physicians' career performance: an evaluative literature review. J Med Educ. 1973;48(4):311-322.

17. Van Berkel H, Schmidt HG. Motivation to commit oneself as a determinant of achievement in problem-based learning. High Educ. 2000;40(2):231-242.
International Journal of General Medicine

\section{Publish your work in this journal}

The International Journal of General Medicine is an international, peer-reviewed open-access journal that focuses on general and internal medicine, pathogenesis, epidemiology, diagnosis, monitoring and treatment protocols. The journal is characterized by the rapid reporting of reviews, original research and clinical studies across all disease areas.

\section{Dovepress}

A key focus is the elucidation of disease processes and management protocols resulting in improved outcomes for the patient. The manuscript management system is completely online and includes a very quick and fair peer-review system. Visit http://www.dovepress.com/ testimonials.php to read real quotes from published authors. 